\title{
Wealth fluctuations and investment in risky assets: The UK micro evidence on households asset allocation
}

\author{
Ivan Paya \\ Economics Department, Lancaster University Management School, LA1 4YX, UK \\ Peng Wang \\ Economics Department, Lancaster University Management School, LA1 4YX, UK
}

\begin{abstract}
:
This paper is the first to examine whether UK households exhibit constant or time-varying relative risk aversion within a microdata panel framework. We analyse whether portfolio allocations in risky assets change in response to fluctuations in wealth. Our set of controls for background wealth is comprehensive, and include, as a novelty in this type of studies, pension wealth. The inference about the risk profile of British households depends upon the relevant measure of background wealth. We do not find support for decreasing relative risk aversion (DRRA). Constant relative risk aversion (CRRA) prevails for the case of liquid wealth, but for the broadest definitions ---those including home equity and pensions--- the evidence favours increasing relative risk aversion (IRRA).
\end{abstract}

JEL Codes: D12, E21, G11

Keywords: relative risk aversion, portfolio choice, panel data, pension wealth

This study used UK household Wealth and Assets Survey that is available from the UK Data Archive. Further documentation about the data that were used in this paper is available from the Lancaster University data archive at: http://dx.doi.org/10.17635/lancaster/researchdata/82 


\section{Introduction}

There is a vast theoretical literature in economics about the importance of risk aversion for the analysis of decision making under risk and uncertainty. The majority of studies that employ utility functions for modelling or calibration purposes assume a particular functional specification. Although the original work of Pratt (1964) and Arrow (1965) suggested that relative risk aversion increases with wealth (IRRA), ${ }^{1}$ the most commonly used utility specification is constant relative risk aversion (CRRA). This property implies that all agents, regardless of their level of wealth, will allocate the same proportion of their wealth to risky assets. However, empirical work that estimates the shape of risk preferences with actual financial and wealth variables, and how those preferences evolve over time, is very limited and there has been no consensus. Empirical studies have provided evidence for all three hypotheses about individual risk aversion: increasing relative risk aversion (IRRA) (Arrow, 1965; Siegel and Hoban, 1982), decreasing relative risk aversion (DRRA) (Bellante and Green 2004; Cohn et al. 1975; Morin and Suarez 1983) and constant relative risk aversion (CRRA) (Friend and Blume 1975).

Most empirical studies have been based on cross-sectional data (Arrow 1965; Bellante and Green 2004; Cohn et al. 1975; Friend and Blume 1975; Morin and Suarez 1983; Siegel and Hoban 1982). This empirical framework cannot, however, identify whether the observed distribution of the risky-asset share across heterogeneous agents comes exclusively from a common form of individual preferences or from different risk aversion parameters conditional on wealth levels. ${ }^{2}$ The evidence gathered by cross-sectional analysis would only be informative of the shape of preferences if risk aversion was independent of wealth. ${ }^{3}$ Work using panel data, on the other hand, does not need to build in such an assumption because it removes the time-invariant

\footnotetext{
${ }^{1}$ In an earlier paper, Markowitz (1952) proposed a value function over changes in wealth that exhibits loss aversion, and that is convex over small gains but concave over larger ones.

${ }^{2}$ This point is formally verified in Chiappori and Paiella (2011, Section 2).

${ }^{3}$ Recent attempts to infer risk profiles within the population have been done using laboratory or field experiments, as well as surveys. See e.g. Vieider et al. (2015) for an international analysis of incentivised as well as survey measures of risk and uncertainty, and how those different measures correlate within contexts and methods, as well as between countries.
} 
unobserved heterogeneity using first differences. This method allows the researcher to distinguish between individual preferences and the variation of risk aversion with wealth.

Two prominent papers in this area are Brunnermeier and Nagel (2008) (BN) in a study of the US, and Chiappori and Paiella (2011) (CP) in a study about Italian households. The latter paper is based on a standard twoperiod portfolio choice model that uses a first-order Taylor series expansion to maximize end-of-period expected utility. Under this set-up the share of risky assets in the portfolio will be constant as long as the coefficient of relative risk aversion remains constant. CP use panel data for Italian Households (SHIW) from 1989 to 2004. They do not find statistically significant elasticity of the risky-asset share, which does not reject the CRRA hypothesis.

While both CP and BN share the same null hypothesis in their empirical analyses - CRRA- BN are more specific about the alternative hypothesis defined as the habit model of consumption. They are the first ones to investigate the standard portfolio allocation model with habits using household panel data. ${ }^{4}$ In their model, agents' welfare depends not only on the absolute consumption level but also on the difference between their consumption and their reference level (Becker and Murphy, 1988) and this generates timevarying relative risk aversion. As a result of this, agents have to invest in risk-free assets to provide sufficient financial resources to ensure that future consumption can always be kept above the level of the habit, which in turn, tie the optimal demand for riskless assets to the slow-moving habit level. Thus, when liquid wealth fluctuates, the optimal risky-asset share should adjust accordingly. In particular, when liquid wealth increases the utility maximization share of risky assets increases, and vice versa. Effectively, relative risk aversion varies with wealth.

Despite the relatively successful role of habit formation in explaining dynamic asset pricing phenomena and macroeconomic stylised facts ${ }^{5}$ the micro

\footnotetext{
${ }^{4}$ Other papers have examined household portfolio composition in a cross-sectional framework, for instance, Blake (1996), and Guiso and Paiella (2008). However, the time variation of panel data allows the analysis to separate household preferences and the joint distribution of risk aversion and wealth.

${ }^{5}$ For instance, the equity premium puzzle (Constantinides, 1990; Campbell and Cochrane, 1999), the equity home bias (Shore and White, 2002), the hump-shaped response of aggregate variables to monetary shocks (Fuhrer, 2000), or countercyclical markups (Ravn, Schmitt-Grohe and Uribe, 2006).
} 
evidence supporting the habit formation consumption model is mixed, and the micro-data evidence that supports the prediction about time varying relative risk aversion is scarce. ${ }^{6}$ BN employ data from the Panel Study of Income Dynamics (PSID) and fail to find a significant positive relationship between wealth and the share of risky assets, concluding against habit formation.

Our paper extends the existing literature on this topic in several aspects. We will, for the first time, use UK household panel data to examine how individuals distribute their portfolio holdings between risky and riskless assets. Our analysis of the elasticity of the risky asset share to total financial wealth will employ the most comprehensive measure of background wealth used in this type of studies. Pension wealth is one of the largest components of wealth and, as a novelty, we will include it, together with home equity, equity in private business and liquid wealth, in one of our measures of total wealth. ${ }^{7}$ While we will initially assume that pension wealth is overall a safe investment, we will also examine households' elasticity of the risky asset share to wealth when it is assumed that pension wealth is part of the risky-asset portfolio. This is particularly relevant given the current tendency for employer-sponsored pension plans to rely more on defined contributions instead of defined benefits, and because of the widespread use of individually managed retirement funds (see Post et al. 2014). The choice of country and time period is also unique as it is the first paper to analyse the nature of households' utility function using panel data for the UK for a sample period that includes episodes of economic and financial turbulence such as the great recession.

Our empirical analysis provides evidence on the specific form of households' preferences for a wide range of assumptions about what is the relevant background wealth investors consider in formulating their investment decisions, from liquid wealth only to liquid wealth in addition to equity in private

\footnotetext{
${ }^{6}$ One of the earliest attempts to test the habit model of consumption was Dynan (2000). He employed household data for the US from the Panel Study of Income Dynamics (PSID) and found no support for the model. A more positive result is found in a study by Ravina (2005) that tests for internal and external habit motives in consumption using the Credit Card Panel for California. Studies that use aggregate data rather than micro data have also found evidence to support the habit model of consumption (e.g. Korniotis, 2010).

${ }^{7}$ As it will become apparent in section 3 below for the case of the UK, while pension is for many households, especially those towards the high end of the distribution, the largest component of wealth, home equity is the largest factor for the majority of households.
} 
business, home equity, and pension wealth. Our results are in general consistent with the evidence provided by BN and CP. We do not find support for the thesis that positive changes in wealth increase the share invested in risky assets.

Support for CRRA or IRRA depends crucially on the measure of wealth and on the classification of pension as either risky or risk free. If the definition

of wealth is restricted to liquid wealth, the marginal effect of wealth changes on the risky asset share is nil, and households would be characterised as exhibiting CRRA. This is also the case when the broadest definiton of wealth is used and pension is characterised as a risky investment. On the other hand, if pension wealth is considered to be risk free, our results support IRRA, implying that a marginal increase in wealth induces households, on average, to rebalance their portfolio proportionately more towards safer assets.

We complete our analysis by exploiting the fact that the cross-sectional analysis can provide an estimation of the joint distribution of wealth and risk aversion if one is ready to assume CRRA. We provide such estimate for the case of liquid wealth and find a negative but small correlation between measured risk aversion and wealth. It is worth noting that, in this case, our average estimate of the coefficient of relative risk aversion is 2.39 , similar to the one obtained by Friend and Blume (1975) for the UK and by CP for Italy, and considerably larger than the one implied by, for instance, logarithmic utility functions.

The rest of the paper is organised as follows. Section 2 sets up the model of asset allocation while section 3 describes the data and discusses the econometric methodology. The empirical results are presented in section 4 . Section 5 discusses the distribution of relative risk aversion across households for the case of liquid wealth, and section 6 concludes.

\section{Asset Allocation Model}

The starting point is the standard two period portfolio choice model. Households with utility function $U$ and initial wealth $W_{t}$ can invest in a risk-free asset with return $R_{f}$, and in a risky asset with random return $R_{m}$ and variance $\sigma^{2}$. The problem of the agent is to choose the optimal share of initial wealth invested in the risky assets, $\alpha_{t}$, that maximizes her expected utility, 


$$
\begin{gathered}
\max _{\{\alpha\}} E\left[U\left(W_{t+1}\right)\right] \\
E\left[U\left(W_{t+1}\right)\right]=E\left\{U\left[W_{t}\left(1+R_{f}+\alpha_{t}\left(R_{m}-R_{f}\right)\right)\right]\right\} .
\end{gathered}
$$

Using a first-order Taylor approximation of the utility function and obtaining the first-order condition of $E\left[U\left(W_{t+1}\right)\right]$ with respect to $\alpha_{t}$ yields the following expression

$$
\alpha_{t}=\frac{1}{\gamma_{t}} \frac{E\left(R_{m}-R_{f}\right)}{\sigma_{m}^{2}},
$$

where $\gamma_{t}$ is the measure of relative risk aversion. The $\log$ form of this equation is

$$
\log \alpha_{t}=\log \frac{E\left(R_{m}-R_{f}\right)}{\sigma_{m}^{2}}-\log \gamma_{t} .
$$

This set up is similar to the one employed by $\mathrm{CP}$ and we refer to their paper for further details and discussion about the multiperiod setting of the model. It follows from this equation that the share of risky assets in the portfolio will be constant as long as the coefficient of relative risk aversion remains constant. Alternatively, variations in the proportion of wealth invested in risky assets would be driven by changes in the relative risk aversion parameter. This is the case, for instance, for IRRA as initially suggested by Arrow $(1965,1971)$.

BN employ an extension of the standard portfolio choice model and incorporate consumption habit. This set up implies DRRA. BN show that, within their framework, the optimal portfolio share, $\alpha_{t}$, varies over time only due to the variation of the ratio of the habit component of consumption over the wealth that has not been used for consumption. It follows from their model that, if habit formation generates time-varying relative risk aversion, one should expect households' share of the risky assets to positively respond to post-consumption wealth. In empirical terms, their model implies that the coefficient of wealth as a regressand of $\alpha_{t}$ should be statistically significant and positive.

\section{Data and Econometric Model}

The dataset is from the UK data service Wealth and Assets Survey (WAS). It is a longitudinal survey of households across Great Britain: Eng- 
land, Wales and Scotland (excluding North of the Caledonian Canal and the Isles of Scilly). WAS gathers comprehensive information about household wealth, collecting data on a wide range of assets and liabilities that private individuals and households in Great Britain hold. We employ all three waves that have been so far released, and each wave spans a period of two years. Wave 1 started in July 2006 where a total of 30,500 households and 53,300 adults were interviewed. Respondents to Wave 1 of the survey were invited to take part in a follow up interview two years later, from July 2008 to June 2010, to create Wave 2. This second wave included 20,000 households and 34,500 adults. The third wave of the survey was conducted between July 2010 and June 2012, and it included 21,451 household and 40,396 individuals. $^{8,9}$ The time period of this analysis is particularly interesting since they cover the last one or two years of the peak of a business cycle and the two years of a very significant recession that includes a financial crisis.

We impose a number of restrictions for those households that will be included in our analysis. ${ }^{10}$ The household has to be involved in at least two continuous waves of surveys and to have positive wealth. We further require that the marital status of the household reference person (HRP) remained unchanged during two consecutive waves of the survey and that there are no assets moved in or out of the household as a consequence of a family member moving in or out of the family. The household is excluded from the analysis if the HRP is retired in a subsequent wave.

\subsection{Definition of variables}

The asset allocation model described in section 2 will be initially estimated using a comprehensive measure of wealth, total wealth, which is the sum of household pension wealth, home equity, equity in private business, liquid wealth and wealth in collectables. This definition of total wealth leaves human capital as the only component of background wealth which is not included.

Total wealth $=$ pension wealth + home equity + equity in private business + liquid wealth + wealth in collectables

\footnotetext{
${ }^{8}$ To make magnitudes comparable over time, we have deflated all income and wealth data by the consumer price index (CPI) into January 2006 British pound.

${ }^{9}$ In both wave 2 and wave 3 , new households and individuals were added into the survey.

${ }^{10}$ These conditions are similar to the ones in the analysis of $\mathrm{BN}$.
} 
WAS only provides the figure for the aggregate household total wealth on pension. ${ }^{11}$ It does not therefore include information about how households allocate their pension funds among the different components. Collard (2009) reviews research, mainly done in the US and UK, about financial decisions in general, and investment behaviour in relation to pensions, in particular. The evidence suggests that UK households, when considering long-term investments such as pensions, are more concerned about minimising financial losses than maximising financial returns. ${ }^{12}$ Furthermore, one of the conclusions in a survey of the UK shows that the majority of respondents considered that a pension scheme linked to the stock market was too risky (Clery et al. 2007). We therefore initially assume that pension wealth is overall an investment in risk free assets. However, pension systems have gone through wide-ranging changes over the last two decades and experienced an increase in the number of defined contribution plans as well as self-invested personal pensions (see e.g. Post et al. 2014). We establish two alternative classifications for pension wealth, risky and risk free, to reflect this tendency and the fact that households may regard the stream of income derived from this investment as not free of uncertainty.

Home equity is defined as the sum of all property values less the value of all mortgages and amounts owed as a result of equity release. We consider housing wealth to be a risky asset (see Banks et al. 2010) which seems particularly relevant around the time of the latest financial crisis of 2007-09 and its aftermath. Equity in private business is defined as the net wealth in private businesses and will also be included as part of the risky portfolio. The liquid wealth is defined as the difference between liquid assets and

\footnotetext{
${ }^{11}$ WAS provides the sum of nine separate components that are not available separately: defined benefits (DB), additional voluntary contributions to DB schemes, employerprovided defined contributions (DC), personal pensions, pensions already in receipt, retained rights in DB-type schemes, retained rights in DC-type schemes, pension funds from which the individual is taking income drawdown, and pensions expected in future from a former spouse. The values of some of these pension components are directly reported by the household during the interview, while some other components were calculated separately. More information about how pension wealth is calculated in WAS can be found at http://www.ons.gov.uk/ons/guide-method/method-quality/specific/economy/wealthand-assets-survey/wealth-and-assets-survey — user-guidance/index.html

${ }^{12}$ Collard also notes that qualitative research for a target group shows that subjects were mostly interested in low-risk investment.
} 
debt. ${ }^{13}$ The wealth in collectables is the total value of collectables own by the household.

To make our study of the UK comparable to previous work, such as BN and $\mathrm{CP}$, that employ narrower definitions of wealth we also consider the following alternative definitions:

$$
\begin{aligned}
& \text { Wealth } 1 \text { = liquid wealth }+ \text { home equity } \\
& \text { Wealth } 2 \text { = liquid wealth }+ \text { equity in private business } \\
& \text { Wealth } 3 \text { (liquid wealth) = liquid assets }- \text { debt }
\end{aligned}
$$

Given the four different measures of wealth the proportion of wealth invested in risky assets, $\alpha_{t}$, which constitutes the dependent variable in the forthcoming empirical analysis, will have four alternative definitions depending on the wealth variable that is used: ${ }^{14}$

Total risky assets share $=\underline{\mathrm{UK} \text { and overseas shares }+ \text { home equity }+ \text { private business equity }+ \text { collectables }}$

Total risky assets share $2=\frac{\text { UK and overseas shares }+ \text { home equity }+ \text { private business equity }+ \text { collectables }+ \text { pension }}{\text { total wealth }}$

Risky assets share $1=\frac{\mathrm{UK} \text { and overseas shares+home equity }}{\text { wealth } 1}$

Risky assets share $2=\frac{\text { UK and overseas shares +private business equity }}{\text { wealth } 2}$

Risky assets share 3 (liquid risky asset share) $=\frac{\text { UK and overseas shares }}{\text { liquid assets }}$

\subsection{Summary statistics}

Table 1 presents pooled cross-section/time-series statistics for all households that satisfy the criteria described above to be included in our sample. Property and pension wealth are not surprisingly the largest components of wealth. Both of their averages together make up about seventy five percent of average total wealth, while average liquid wealth only represents around fifteen percent. Wealth in stock market equity and private businesses is heavily skewed towards the top end of the household distribution. Thirteen

\footnotetext{
${ }^{13}$ Liquid assets are the sum of holdings of UK and overseas shares plus riskless assets that include ISAs, cash-like assets, holdings of bonds, and the value of endowments purchased to repay mortgages. The debt comprises non-mortgage debt such as credit card debt and consumer loans.

${ }^{14}$ In line with several other studies, we use liquid assets, rather than liquid wealth, to calculate the risky asset share (risky assets share 3). This is because liquid wealth could be very close to zero for some households.
} 
percent of the households in the sample entered the stock market in subsequent waves when they were not holding any stock at the time of the previous wave. Twenty-five percent of the sample did leave the market in subsequent waves while they were holding stocks in a previous wave. The market participants are defined as households holding stock market equity in consecutive waves.

Thirty one percent of the observations are market participants. Our empirical analysis is based on those households and table 2 displays the summary statistics. ${ }^{15}$ The stylised facts are very similar to the ones for the full sample except for that the averages are higher. This implies that those who participate in the stock market have, on average, higher income and wealth. The liquid risky asset share for this subset of households is much higher than for the whole sample, $21.8 \%$ relative to $8.4 \%$. Over the three-wave period, total wealth increases, but all other three measures of wealth decrease.

We finish the discussion about the descriptive statistics by comparing data from the UK and the US. Following earlier work in this area, we use US household wealth data from the PSID. The period used is 1999-2003 that includes three two-year period survey waves. We impose similar restrictions to include households in the analysis. ${ }^{16}$ The PSID does not provide data on pensions. The data displayed in tables 3 and 4 reveal some interesting differences across the two countries. The two most notable ones are (i) the composition of household wealth: households in the US hold a higher proportion of liquid assets and equity of their private businesses, while households in the UK hold higher proportions of home equity; and (ii) households in the US hold a much higher proportion of liquid risky assets, $33.7 \%$ for the whole US sample relative to $8.4 \%$ for the UK.

\subsection{Econometric Model}

The aim of the empirical analysis is to find out what type of risk aversion discussed above is supported by the data, DRRA, CRRA or IRRA. In order

\footnotetext{
${ }^{15}$ For the cross-section analysis, market participants are defined as households holding stock market equity at current wave of survey (at time $t$ ). The summary statistics for these households are available upon request.

${ }^{16}$ In particular, we require marital status of the HRP, employment status of the HRP, and structure of household to stay the same. We end up including 3,914 observations. All the wealth and income data are inflated into 2006 dollars. The US data is collected in 1999, 2001 and 2003.
} 
to correctly specify the econometric model we need to address issues such as the presence of external factors affecting both wealth and risky-asset shares, factors affecting all households simultaneously, self-selection of the sample, and possible measurement error.

First, we consider factors that may cause common movements in the level of wealth, $W_{t}$, and the share of risky assets, $\alpha_{t}$. This is the case of life-cycle components that can be considered to generate a correlated deterministic pattern over time between an agent's wealth and the proportion invested in risky assets. The life-cycle controls will be collectively denoted as $q_{t-k}$, with $k=2$ years, and include the following variables:

Life-cycle controls: age and age squared of the HRP, indicators for education for the HRP, interaction terms of education level with age and age squared, dummy variables for the gender of the HRP and their interaction with age and age squared, marital status, health status, the number of children in the household, the number of people in the household, log of family income at previous wave, and the value of inheritance received within two years before the previous wave of the survey. The value of inheritance is scaled by income to adjust for the fact that a given amount of inheritance has a different effect for households with different levels of income.

We consider another set of control variables to capture major changes in the composition of the household or the asset ownership that could lead to preference shifts which could possibly be correlated with changes in the share of risky assets. These variables will be collectively denoted by $\Delta h_{t}$ and include the following

Preference shifters: changes in family size, changes in the number of children in the household, dummy for business ownership and a dummy variable that indicates if the family acquired a house during the period of the survey. ${ }^{17}$

The empirical model also needs to control for factors that would affect all households simultaneously. The reason is that, for those factors, the portfolio adjustment would be made via prices rather than quantities. To isolate the effect of habit, factors that change aggregate wealth and asset holding should be controlled for, and these will be denoted by $A_{t}$ :

Aggregate changes: time fixed effects, and interaction of year and regional dummies.

\footnotetext{
${ }^{17}$ Preference shifters are not employed in the cross-sectional model.
} 
The econometric model is therefore based on the following regression,

$$
\Delta \alpha_{t}=\beta q_{t-k}+\theta \Delta h_{t}+\phi A_{t}+\rho \Delta w_{t}+\varepsilon_{t} .
$$

The issue of measurement error in both the risky-asset share, $\alpha_{t}$, and wealth, $w_{t}$, in our regression equation is discussed in BN (section 2.3). In order to avoid biases and inconsistencies in the parameter estimates we employ a two-stage least square (TSLS) method to estimate $\rho$. The instrumental variables for $\triangle w_{t}$ have to be uncorrelated with the residuals, but (partially) correlated with changes in household wealth. We follow BN and choose three instruments. The first two are quantile dummies for household income growth between two consecutive waves, and the third one is inheritance receipts between the current wave of the survey and the previous wave (between $t$ and $t-2) .{ }^{18}$ These instruments are taken from survey questions, different from the components of $W_{t}$, but correlated with household wealth. In the results section below we still report both the OLS and TSLS because even though the latter method deals with the problem of measurement error, their estimates are less precise than the OLS ones.

Another econometric issue is that the regression only includes stock market participants. This could lead to sample selection biases, since the households who are included in the sample are not randomly selected. They are observed because those households participate in the stock market. Ignoring the decisions of entry to or exit from the risky-asset market may lead to misleading inference. In order to tackle this problem, regression results from the Heckman two-step procedure are also reported. ${ }^{19}$

\section{Empirical results}

Prior to estimating the econometric model described above we investigate a more general question about portfolio decisions made by UK households. We analyse whether changes in wealth affect their decisions to enter or exit the stock market. Although the results of this analysis are not informative

\footnotetext{
${ }^{18}$ The instrumental variables for the regression on the level are inheritance and total household income.

${ }^{19}$ For the Heckman two-step model we use inheritance receipts between $t$ and $t-2$ as an exclusion restriction (instrument) that affects the dichotomic variable in the first stage but not the outcome in the second stage.
} 
about the degree of portfolio reallocation induced by changes in wealth, they do, in any case, provide an interesting stylised fact.

\subsection{Stock market participation}

The decision to add stock market equity to a portfolio that does not contain any, or to sell all the shares held in a portfolio at one point in time is different from how much a portfolio that already includes risky assets should be readjusted due to changes in wealth. The decision about to enter or exit the stock market depends not only on the attitude toward risk but also on issues such as fixed costs of participation (see Paiella 2007). The results obtained from this analysis will therefore not be conclusive about time-varying risk aversion but are, in any case, informative about portfolio choices.

We employ a probit model to test whether the entry and exit decision made by UK households over the period 2006-2012 is influenced by changes in wealth. The results reported in table 5 are in line with expectations. The regressions include all the life-cycle, preference shifters and aggregate change controls discussed in the previous section. The results show that increases in wealth marginally increase the likelihood of households to enter the stock market, and decreases the likelihood of leaving the market. ${ }^{20}$ The magnitudes of these point estimates are small, but they are not negligible either, and are similar to the ones for the US reported in BN.

\subsection{Total wealth}

\subsubsection{Cross sectional analysis}

One of the contributions of this paper is to add pension wealth as part of the background wealth of the agents. Tables 1 and 2 show that pension wealth accounts for around forty percent of average total wealth. However, previous research in this area has not been able to analyse portfolio decisions that include pension wealth. WAS does provide researchers with this opportunity because it reports the value of pension wealth for UK households. This allows us to construct a comprehensive measure of household total wealth, which is the sum of liquid wealth, home equity, private business equity, collectables, and pension. Table 6 displays the results of the

\footnotetext{
${ }^{20}$ Wealth is defined here as total wealth. We also employ the probit regression on the other three levels of wealth and found similar results.
} 
cross-sectional analysis regression for the case of total wealth and total risky asset share 1. The second column reports the results from the ordinary least squares (OLS) regression. The estimated coefficient is negative but statistically insignificant. However, when the Heckman two-stage (HT) regression is implemented to address sample selection bias, the point estimate becomes significantly negative. In addition to this, significance of the Mills ratio indicates further that sample selection bias may be present in the cross-sectional analysis. The TSLS estimates reported in column four also show a significantly negative coefficient. The first stage results in panel B indicate that the instrumental variables have a significant partial correlation with total wealth, with the expected signs, and high F-statistics.

Table 6 columns five to ten report the regression results based on two restricted samples. The first one excludes households with wealth less than 5,000 pounds; and the second restricted sample excludes those whose wealth changes are less than $25 \%$. In other words, the first restricted sample focuses on relatively wealthy households and the second one on households with large wealth fluctuations. This robustness check deals with the potential nonlinearity in portfolio adjustment derived from transaction costs. The results from the restricted samples are largely unchanged compared to those from the unrestricted sample, suggesting that the higher the total wealth the lower the household investments in risky assets. In other words, our results from cross-sectional regression overall suggest IRRA.

\subsubsection{First differences analysis}

One of the concerns related to the empirical work based on cross-sectional data is that individuals' risk preferences may be heterogeneous. This means that the cross-sectional distribution of the share of risky assets in households' portfolios depends not only on the form of individual preferences but also on the joint distribution of wealth and risk aversion in the population. The cross-sectional data cannot disentangle these two effects due to its lack of time variation, and therefore potentially telling nothing about the shape of risk preferences. This problem can be solved by using panel data to estimate a first-difference model to eliminate the effects of preference heterogeneity.

The point estimates shown in table 7 are all significantly negative regardless of the estimation method or sample restrictions. The similarity of OLS and HT estimates and the insignificance of the Mills ratio indicate that the source of self-selection may be eliminated by taking first differences. The TSLS estimates are larger in absolute value, indicating the possibility of 
measurement error in the OLS and HT estimates. ${ }^{21}$

Overall, results from table 7 suggest a negative risky assets share elasticity to total wealth, providing further evidence in support of IRRA. This finding implies that if, for example, total wealth were to increase, households would proportionally increase their investment in safe assets such as bonds or pensions, or put it differently, they would proportionally reduce their exposure to risky assets such as shares, private businesses or home equity (also by, possibly, increasing their leverage in home-related debt) ${ }^{22}$

\subsubsection{Pension as risky investment}

WAS does not provide separate data on the different elements of pension wealth which naturally differ in terms of their riskiness. Pension plans have experienced considerable changes over the last two decades and there is a tendency towards defined contribution as well as self-invested personal pensions as discussed in previous sections. We take this fact into consideration by considering an alternative specification. We include pensions as part of the risky portfolio and estimate the elasticity of the risky asset share to wealth using the variable Total risky assets share 2. Table 8 presents the estimates for both the cross sectional and first differences data. ${ }^{23}$ In this case CRRA cannot be rejected. This result is intuitive because, relative to tables 6 and 7 , households now would not proportionately increase their share of risk-free assets as their wealth increases if investment and stock in pensions are considered to be risky. Under this assumption, households' elasticity is zero and the share of risky assets is not affected by changes in wealth.

\subsection{Net equity in housing}

Descriptive statistics show that net home equity accounts, on average, for roughly one third of households' total net wealth. Moreover, more than

\footnotetext{
${ }^{21}$ The first stage F-statistics for the TSLS have a value lower than ten, which may indicate weak instruments. We therefore re-run our tests with a limited information maximum likelihood (LIML) estimator and we obtained similar results. Overall, our TSLS results in the first-difference analysis do not seem to be much affected by the weak instruments problem. The results are available upon request.

${ }^{22}$ Guiso and Paiella (2008) provide empirical evidence of IRRA in their study of households in Italy. They use a direct survey measure of absolute risk aversion to examine the relationship between wealth and risk aversion.

${ }^{23}$ Note that the first stage regressions in both cases are the same as the ones reported in tables 6 and 7 .
} 
ninety percent of households in our sample hold home equity in their portfolio making it a very important asset to examine households' investment strategies.

The analysis based on the first-difference model shown in table 9 where wealth is defined as liquid wealth plus home equity (wealth 1) finds evidence of a negative relationship between changes in wealth and relative risk aversion, which is in line with IRRA. The size of the negative coefficients is slightly smaller than those in the table for total wealth. It is however worth noting that this result is not entirely robust to subsamples for high wealth or large wealth changes when TSLS is employed. For those cases, CRRA cannot be rejected. ${ }^{24}$

\subsection{Equity in private business}

Equity in private business is a less liquid investment than other assets included in the definition of wealth. This is because of the indivisibility of the business equity holding and its lack of tradability which also makes these assets riskier and with higher entry requirements. The proportion of households that invest in private business is only about ten percent of the stock market participants.

Table 10 reports the analysis in first differences using a measure of wealth that includes the holding of private equity in addition to liquid wealth (wealth 2). The OLS and Heckman two-stage results generate significantly negative coefficients, but once measurement error is considered, the coefficient becomes insignificant. The results from the two restricted samples are highly consistent with the ones for the full sample. This analysis indicates that fluctuations in wealth 2 are unlikely to affect the risky asset share and there is no overwhelming evidence to reject the CRRA hypothesis. ${ }^{25}$

\footnotetext{
${ }^{24}$ The results of the cross-section analysis, not reported here but available upon request, show that the point estimate from the OLS regression is not significant. However, if sample selection bias and measurement errors are considered, the point estimates become significantly negative, indicating a positive relationship between wealth and relative risk aversion. This result may be explained by the fact that, in our UK sample, home equity accounts for a larger fraction of wealth in low-wealth households than it is in high-wealth households. However, this inference is not entirely robust because the results from the two restricted samples point towards the prediction of CRRA.

${ }^{25}$ For the analysis in levels, not reported here, the estimated coefficients for the full sample are insignificant in all three estimation methods and the results are largely the same when the two restricted samples are used.
} 


\subsection{Liquid wealth only}

The definition of wealth most commonly analysed in previous studies is liquid wealth -denoted here as wealth 3 . Table 11 displays the results of firstdifference regressions for the case of liquid wealth. The estimates of TSLS are insignificant in all the three samples, indicating that CRRA cannot be rejected as the households' risk preference model. This result is similar to the other two panel studies based on liquid wealth, BN for the case of US and $\mathrm{CP}$ for the case of Italian households. ${ }^{26}$

A conclusion that emerges from the results in this section is that the risk profile of UK households would be characterised differently depending on what is considered to be the most appropriate measure of wealth. Our results suggest, overall, that households do not significantly change their share of risky assets when narrow, and therefore, liquid levels of wealth change. ${ }^{27,28}$

\section{Distribution of risk aversion}

There are many instances where economic modellers and analysts focus on a narrow definition of wealth such as liquid wealth, and it is therefore worth examining the correlation between risk aversion and wealth levels under the assumption of CRRA for the case of UK households.

\footnotetext{
${ }^{26}$ The point estimates of the estimation of the regression in levels for liquid wealth are similar under the three different samples. The OLS and HT estimates are significantly positive, indicating DRRA; while the TSLS estimate is statistically insignificant, suggesting that CRRA cannot be rejected.

${ }^{27}$ The cross-sectional analysis undertaken in this paper for all the different definitions of wealth (available upon request) shows ambiguous results that are conditional on the definition of wealth. The point estimates change from negative to zero or to positive switching, accordingly, from IRRA to CRRA or to DRRA. This finding is consistent with those in the early empirical literature based on cross-sectional data, such as Cohn et al. (1975), Friend and Blume (1975), and Siegel and Hoban (1982). However, as pointed out above, the cross-sectional analysis may be uninformative under heterogeneous preferences.

${ }^{28}$ Besides the two restricted samples reported in the tables -high levels of wealth and large changes in wealth, we conduct further robustness tests that are available upon request. The results are generally similar to those above and, therefore, we only briefly summarise the alternative sub-samples employed. We check the sensitivity of the results to different age groups and house ownership. Another variation is the use of the ratio of stock holdings over liquid wealth, rather than over liquid assets, for the definition of liquid risky assets share.
} 
Assuming that agents hold the same market portfolio and that they have homogeneous expectations, the normalized excess return term in equations (2) and (3) is identical for all households. The distribution of relative risk aversion can, in this case, be determined from the distribution of the share of risky assets. We start with equation (3) described above,

$$
\log \alpha_{t}=\log \frac{E\left(R_{m}-R_{f}\right)}{\sigma_{m}^{2}}-\log \gamma_{t} .
$$

This expression implies that, for the set of households with positive risky assets holdings, the distribution of shares identifies that of risk aversion up to a scale factor of $E\left[R_{m}-R_{f}\right] / \sigma_{m}^{2}$. Following Chiappori and Paiella (2011), we conduct a rough calibration and set $E\left[R_{m}-R_{f}\right]=0.04$ and $\sigma_{m}^{2}=0.2$. Accordingly, $\log \gamma_{t}=\log \left(1 / \alpha_{t}\right)$. The distribution of relative risk aversion is shown in figure 1. More than ninety percent of the observations are associated with a relative risk aversion lower than 5 , and the mean is 2.39. This mean estimate is similar to the one found by Friend and Blume (1975) and it implies that investors require a substantially larger premium to hold equities or other risky assets than they would if their attitudes toward risk were described by commonly used utility functions such as the logarithmic one. The sample correlation between measured risk aversion and wealth is -0.09 . This small negative correlation indicates that high wealth households are relatively less risk averse under the assumption of CRRA for the case of liquid wealth.

To shed more light on the covariance between estimated risk aversion and wealth, we split the sample based on household wealth and plot the distribution of measured relative risk aversion for the lower and upper quartiles in figure 2. Low-wealth households are associated with higher mean and median, indicating a higher risk aversion; while the high-wealth households are generally less risk averse. This result is consistent with the evidence from the cross-sectional regression analysis based on liquid wealth. In the absence of a time dimension, cross-sectional analysis of UK households would conclude that relative risk aversion is decreasing with wealth. However, this conclusion would be misleading since we have shown that the distribution of risk aversion is not independent of wealth - although with a quantitatively small coefficient, and that preferences across households are heterogeneous. ${ }^{29}$

\footnotetext{
${ }^{29}$ Another case where CRRA cannot be rejected in our empirical analysis and therefore it would be possible to identify the risk aversion parameter (up to a scale factor) using the
} 


\section{Conclusions}

We employ data from the Wealth and Assets Survey (WAS) to examine, for the first time, UK households portfolio allocations in a multi-period setting. The time dimension of the dataset allows researchers to undertake the analysis of the marginal effect of changes in wealth on the decision to invest in risky assets without the need to assume, contrary to cross-sectional analysis, that risk aversion is independent of the distribution of wealth.

Although the analysis for narrow definitions of wealth, such as liquid wealth, is interesting in itself -liquidity decisions-, a more comprehensive study of households' risk preferences needs to control for as many components of background wealth as possible. A novelty of our study is the inclusion of pension wealth which, together with home equity, private business equity, collectables and liquid wealth, makes it the broadest range of wealth employed in this type of studies.

We highlight the following results. First, we do not find evidence of DRRA which is suggested by, for instance, models of consumption habit formation. Second, the inference about risk preferences depends crucially on the control for background wealth. While empirical support for CRRA is found for narrower measures of wealth - liquid wealth and liquid wealth plus private business equity; IRRA is consistent with broader definitions of wealth - those including home equity and pension wealth. The classification of pension wealth as a risky investment rather than risk free would switch the estimate of the elasticity of the risky asset share to total financial wealth to zero, supporting a CRRA specification of the utility function. Third, these results are in general robust to restricted samples of high levels of wealth and large changes in wealth, although, in some cases, they are sensitive to methods dealing with sample selection bias and measurement error.

\section{References}

[1] Arrow, K.J., 1965. Aspects of the theory of risk bearing. Yrjo Jahnsson Saatio, Helsinki.

distribution of risky assets share is total risky asset share 2, i.e., when both home equity and pension wealth are also part of the risky portfolio. Results are not reported here for space consideration but available from the authors upon request. In this case, there is still a negative but small correlation between risk aversion and wealth levels (-0.04) and the implied mean risk aversion parameter is 0.17 . 
[2] Arrow, K.J., 1971. Essays in the theory of risk-bearing. Chicago: Markham Publishing Company.

[3] Banks, J., Blundell, R., Oldfield, Z. and Smith, J.P., 2010. Housing price volatility and downsizing in later life. In D. A. Wise (ed.), Research Findings in the Economics of Aging. Chicago: University of Chicago Press, pp. 337-84.

[4] Becker, G.S., Murphy, K.M., 1988. A theory of rational addiction. Journal of Political Economy 96, 675-700.

[5] Bellante, D., Green, C.A., 2004. Relative risk aversion among the elderly. Review of Financial Economics 13, 269-281

[6] Blake, C., 1996. Efficiency, risk aversion and portfolio insurance: An analysis of financial asset portfolios held by investors in the United Kingdom. The Economic Journal 106, 1175-1192.

[7] Brunnermeier, M.K., Nagel, S., 2008. Do wealth fluctuations generate time-varying risk aversion? Micro-evidence on individuals. American Economic Review 98, 713-36.

[8] Campbell, J.Y., Cochrane, J.H., 1999. By force of habit: A consumptionbased explanation of aggregate stock market behavior. Journal of Political Economy 107, 205-251.

[9] Chiappori, P.A., Paiella, M., 2011. Relative risk aversion is constant: Evidence from panel data. Journal of the European Economic Association 9, 1021-1052.

[10] Clery, E., McKay, S., Phillips, M., Robinson, C., 2007. Attitudes to pensions: the 2006 Survey. Research Report No. 434. Leeds: Stationery Office.

[11] Cohn, R.A., Lewellen, W.G., Lease, R.C., Schlarbaum, G.G., 1975. Individual investor risk aversion and investment portfolio composition. Journal of Finance 30, 605-620

[12] Collard, S., 2009. Individual investment behaviour: A brief review of research. Final report, PFRC. 
[13] Constantinides, G.M., 1990. Habit formation: A resolution of the equity premium puzzle. Journal of Political Economy 98, 519-543.

[14] Dynan, K.E., 2000. Habit formation in consumer preferences: Evidence from panel data. American Economic Review 90, 391-406.

[15] Friend, I., Blume, M.E., 1975. The demand for risky assets. American Economic Review 65, 900-922.

[16] Fuhrer, J.C., 2000. Habit formation in consumption and its implications for monetary-policy models. American Economic Review 90, 367-390.

[17] Guiso, L., Paiella, M., 2008. Risk aversion, wealth and background risk. Journal of the European Economic Association 6, 1109-1150.

[18] Korniotis, G.M., 2010. Estimating panel models with internal and external habit formation. Journal of Business and Economic Statistics 28, 145-158.

[19] Markowitz, H., 1952. The utility of wealth. Journal of Political Economy $60,151-158$.

[20] Morin, R.A., Suarez, A.F., 1983. Risk aversion revisited. The Journal of Finance 38, 1201-1216.

[21] Paiella, M., 2007. The forgone gains of incomplete portfolios. The Review of Financial Studies 20, 1623-1646.

[22] Post, T., Grundl, H., Schmit, J.T., and Zimmer, A., 2014. The impact of investment behaviour for individual welfare. Economica 81, 15-47.

[23] Pratt, J.W., 1964. Risk aversion in the small and in the large. Econometrica $32,122-136$.

[24] Ravina, E., 2005. Keeping Up with the Joneses: Evidence from Micro Data. Working paper, Northwestern University.

[25] Ravn, M.O., Schmitt-Grohe, S., Uribe, M., 2006. Deep habits. Review of Economic Studies 73, 195-218.

[26] Shore, S.H., White, J.S., 2002. External habit formation and the home bias puzzle. Working paper, Harvard University. 
[27] Siegel, F.W., Hoban, J.P., 1982. Relative risk aversion revisited. Review of Economics and Statistics 64, 481-487.

[28] Vieider, F.M., Lefebvre, M., Bouchouicha, R., Chmura, T., Hakimov, R., Krawczyk, M., Martinsson, P., 2015. Common components of risk and uncertainty attitudes across contexts and domains: Evidence from 30 countries. Journal of the European Economic Association 13, 421-452. 
Table 1: Summary Statistics A: full sample, UK

\begin{tabular}{rrrrrr}
\hline \hline & \multicolumn{3}{c}{ Full sample } & & \\
\hline Variable & Mean & $\begin{array}{r}\text { Tenth } \\
\text { percentile }\end{array}$ & Median & $\begin{array}{r}\text { Ninetieth } \\
\text { percentile }\end{array}$ & N \\
\hline Liquid wealth & 85,345 & 2,483 & 31,438 & 194,662 & 6,712 \\
Property wealth & 207,364 & 16,521 & 143,201 & 416,053 & 6,712 \\
Business wealth & 59,347 & 0 & 0 & 2,553 & 6,712 \\
Pension wealth & 227,153 & 2,843 & 100,110 & 539,052 & 6,712 \\
Collectables & 2,686 & 0 & 0 & 2,490 & 6,712 \\
Total wealth & 581,894 & 73,902 & 337,486 & $1,129,614$ & 6,712 \\
Stock value & 18,713 & 0 & 0 & 26,776 & 6,712 \\
Total risky asset share 1 & 0.481 & 0.112 & 0.479 & 0.851 & 6,712 \\
Total risky asset share 2 & 0.850 & 0.669 & 0.910 & 0.987 & 6,712 \\
Risky asset share 1 & 0.733 & 0.330 & 0.820 & 0.973 & 6,712 \\
Risky asset share 2 & 0.141 & 0 & 0 & 0.574 & 6,712 \\
Liquid risky asset share & 0.084 & 0 & 0 & 0.317 & 6,712 \\
Market participation & 0.31 & 0 & 0 & 1 & 6,712 \\
Stock market entry & 0.13 & 0 & 0 & 1 & 3,931 \\
Stock market exit & 0.25 & 0 & 0 & 1 & 2,781 \\
\hline \hline
\end{tabular}


Table 2: Summary Statistics B : stock market participants, UK

\begin{tabular}{|c|c|c|c|c|c|}
\hline \multicolumn{6}{|c|}{ Stock Market Participants } \\
\hline Variable & Mean & $\begin{array}{r}\text { Tenth } \\
\text { percentile }\end{array}$ & Median & $\begin{array}{l}\text { Ninetieth } \\
\text { percentile }\end{array}$ & $\mathrm{N}$ \\
\hline Liquid wealth & 162,378 & 12,770 & 80,445 & 350,501 & 2,098 \\
\hline Property wealth & 305,098 & 74,347 & 207,484 & 605,315 & 2,098 \\
\hline Business wealth & 61,904 & 0 & 0 & 25,230 & 2,098 \\
\hline Pension wealth & 338,162 & 22,516 & 170,222 & 734,001 & 2,098 \\
\hline Collectables & 5,087 & 0 & 0 & 4,695 & 2,098 \\
\hline Total wealth & 872,628 & 195,481 & 578,432 & $1,646,741$ & 2,098 \\
\hline Stock value & 51,125 & 413 & 7,138 & 105,269 & 2,098 \\
\hline Total risky asset share 1 & 0.496 & 0.218 & 0.483 & 0.806 & 2,098 \\
\hline Total risky asset share 2 & 0.861 & 0.710 & 0.893 & 0.980 & 2,098 \\
\hline Risky asset share 1 & 0.766 & 0.527 & 0.800 & 0.962 & 2,098 \\
\hline Risky asset share 2 & 0.290 & 0.103 & 0.157 & 0.774 & 2,098 \\
\hline Liquid risky asset share & 0.218 & 0.008 & 0.117 & 0.606 & 2,098 \\
\hline$\Delta \log$ total wealth & 0.034 & -0.408 & 0.034 & 0.499 & 2,098 \\
\hline$\Delta \log$ wealth 1 & -0.022 & -0.401 & -0.037 & 0.388 & 2,098 \\
\hline$\Delta \log$ wealth 2 & -0.031 & -1.076 & -0.016 & 0.990 & 2,098 \\
\hline$\Delta \log$ liquid wealth & -0.034 & -1.031 & -0.015 & 0.937 & 2,098 \\
\hline$\Delta$ total risky asset share 1 & -0.029 & -0.225 & -0.031 & 0.170 & 2,098 \\
\hline$\Delta$ total risky asset share 2 & 0.002 & -0.118 & 0.001 & 0.131 & 2,098 \\
\hline$\Delta$ risky asset share 1 & -0.006 & -0.175 & -0.010 & 0.167 & 2,098 \\
\hline$\Delta$ risky asset share 2 & -0.028 & -0.353 & -0.014 & 0.301 & 2,098 \\
\hline$\Delta$ liquid risky asset share & -0.026 & -0.317 & -0.015 & 0.241 & 2,098 \\
\hline
\end{tabular}


Table 3: Summary Statistics C: full sample, US

\begin{tabular}{|c|c|c|c|c|c|}
\hline \multicolumn{6}{|c|}{ Full Sample } \\
\hline Variable & Mean & $\begin{array}{r}\text { Tenth } \\
\text { percentile }\end{array}$ & Median & $\begin{array}{l}\text { Ninetieth } \\
\text { percentile }\end{array}$ & $\mathrm{N}$ \\
\hline Liquid wealth & 194,509 & 2,202 & 49,502 & 394,533 & 3,914 \\
\hline Property wealth & 125,058 & 0 & 78,551 & 293,436 & 3,914 \\
\hline Business wealth & 82,094 & 0 & 0 & 54,913 & 3,914 \\
\hline Financial wealth & 476,560 & 18,669 & 197,686 & 895,532 & 3,914 \\
\hline Stock value & 174,206 & 0 & 25,094 & 318,612 & 3,914 \\
\hline Liquid risky asset share & 0.337 & 0 & 0.224 & 0.912 & 3,914 \\
\hline Financial risky asset share & 0.668 & 0 & 0.751 & 0.988 & 3,914 \\
\hline
\end{tabular}

Table 4: Summary Statistics D: stock market participants, US

\begin{tabular}{rrrrrr}
\hline \hline \multicolumn{6}{c}{ Stock Market Participants } \\
\hline Variable & Mean & $\begin{array}{c}\text { Tenth } \\
\text { percentile }\end{array}$ & Median & $\begin{array}{r}\text { Ninetieth } \\
\text { percentile }\end{array}$ & $\mathrm{N}$ \\
\hline Liquid wealth & 325,217 & 17,566 & 119,676 & 609,059 & 1,798 \\
Property wealth & 176,049 & 0 & 120,827 & 394,274 & 1,798 \\
Business wealth & 114,755 & 0 & 0 & 110,485 & 1,798 \\
Financial wealth & 728,542 & 76,350 & 344,714 & $1,242,264$ & 1,798 \\
Stock value & 238,237 & 5,491 & 60,276 & 416,193 & 1,798 \\
Liquid risky asset share & 0.575 & 0.154 & 0.576 & 0.962 & 1,798 \\
Financial risky asset share & 0.779 & 0.408 & 0.815 & 0.997 & 1,798 \\
$\Delta$ log liquid wealth & 0.092 & -1.244 & 0.034 & 1.468 & 1,798 \\
$\Delta$ log financial wealth & 0.121 & -0.646 & 0.113 & 0.895 & 1,798 \\
$\Delta$ liquid risky asset share & -0.018 & -0.467 & -0.006 & 0.402 & 1,798 \\
$\Delta$ financial risky asset share & 0.007 & -0.337 & -0.002 & 0.325 & 1,798 \\
\hline \hline
\end{tabular}


Table 5: Stock market entry and exit

\begin{tabular}{ccc}
\hline \hline & Entry & Exit \\
\hline$\Delta \log$ total wealth & $0.024^{*}$ & $-0.065^{*}$ \\
& $(0.003)$ & $(0.008)$ \\
Preference shifters & $\mathrm{Y}$ & $\mathrm{Y}$ \\
Life-cycle controls & $\mathrm{Y}$ & $\mathrm{Y}$ \\
Year-region FE & $\mathrm{Y}$ & $\mathrm{Y}$ \\
Pseudo $R^{2}$ & 0.077 & 0.080 \\
$\mathrm{~N}$ & 3,931 & 2,778 \\
\hline \hline
\end{tabular}

Notes: An asterisk $(*)$ denotes significance at the five percent level. Estimates are marginal effects. 


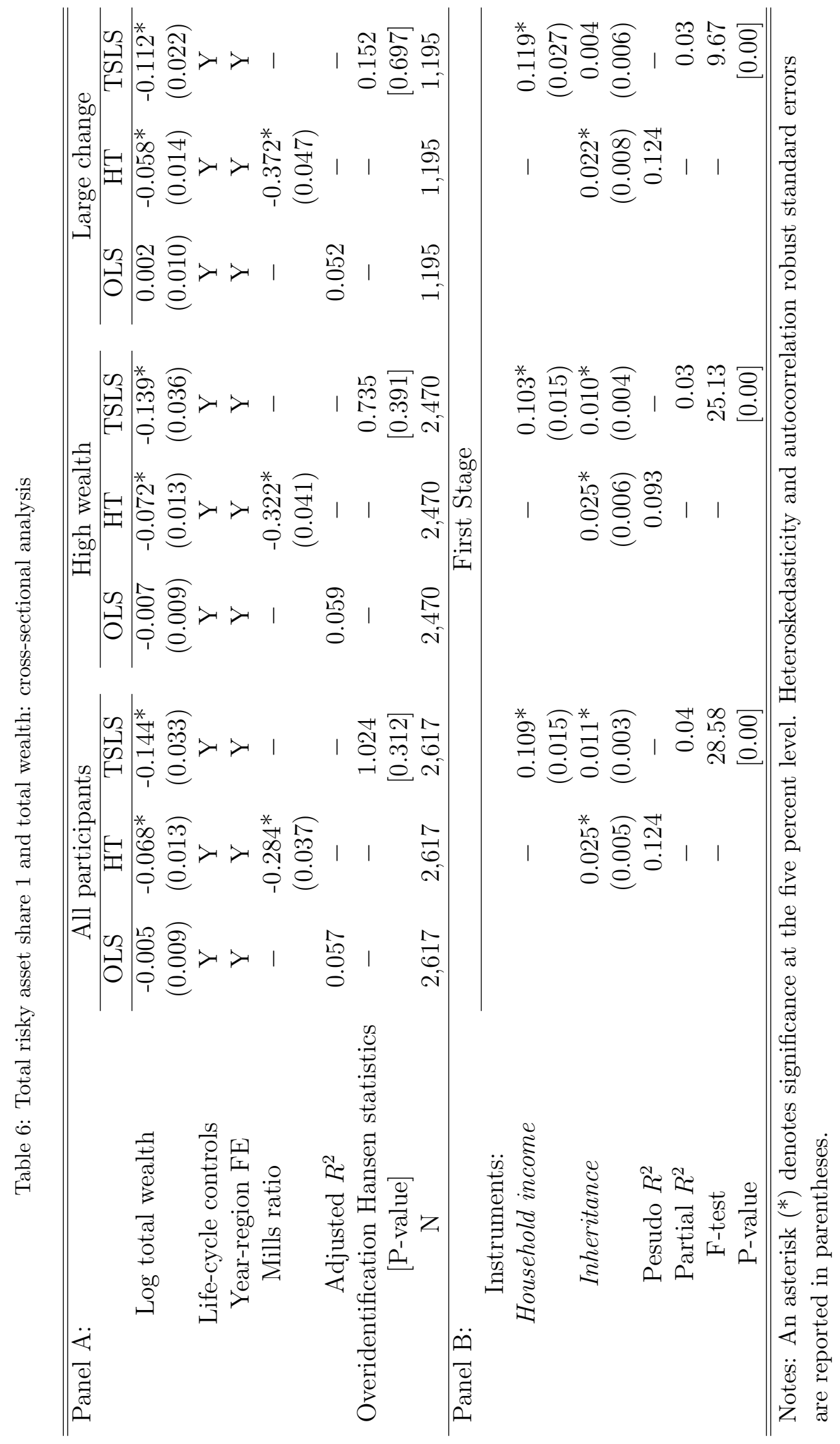




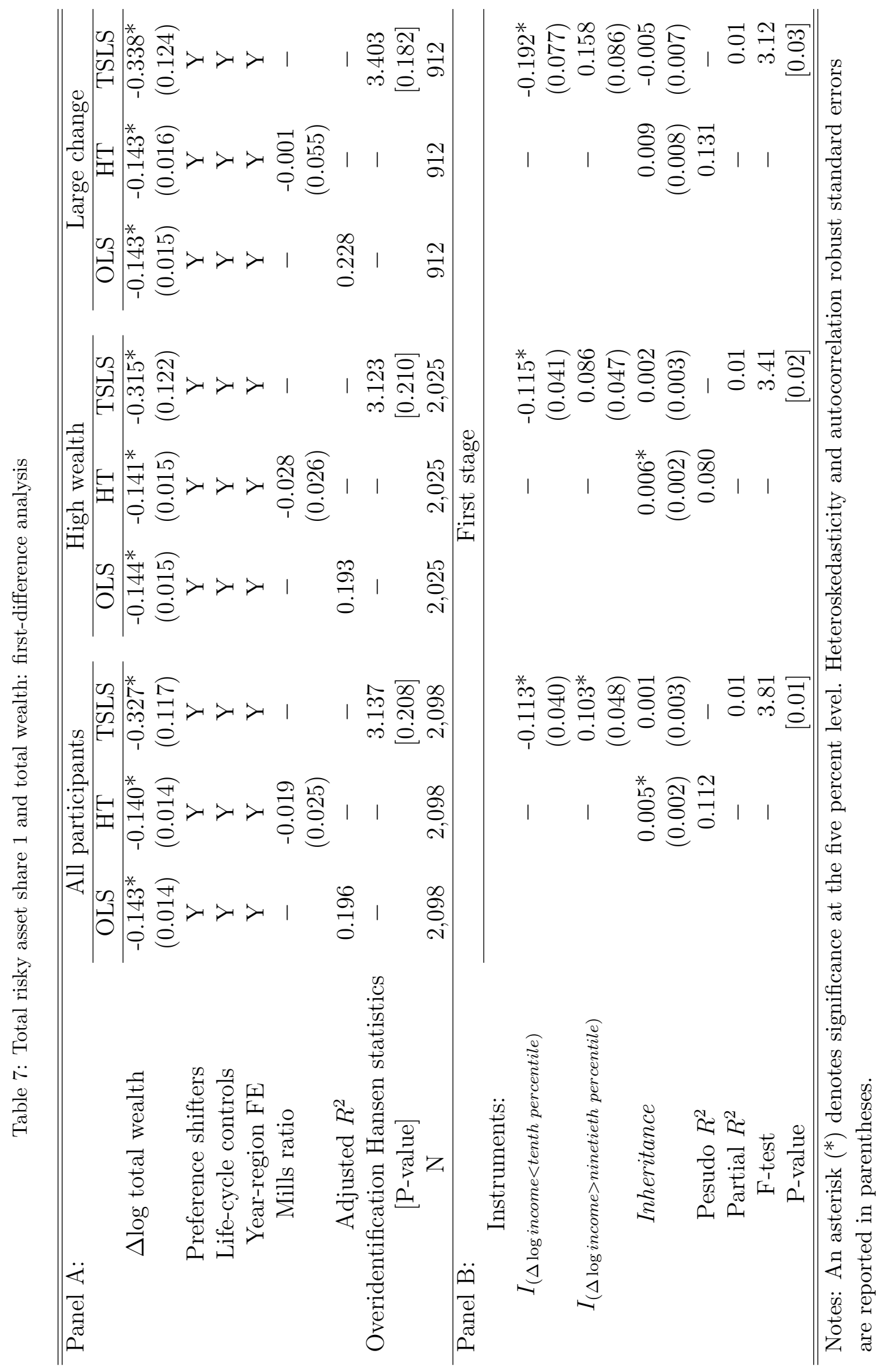




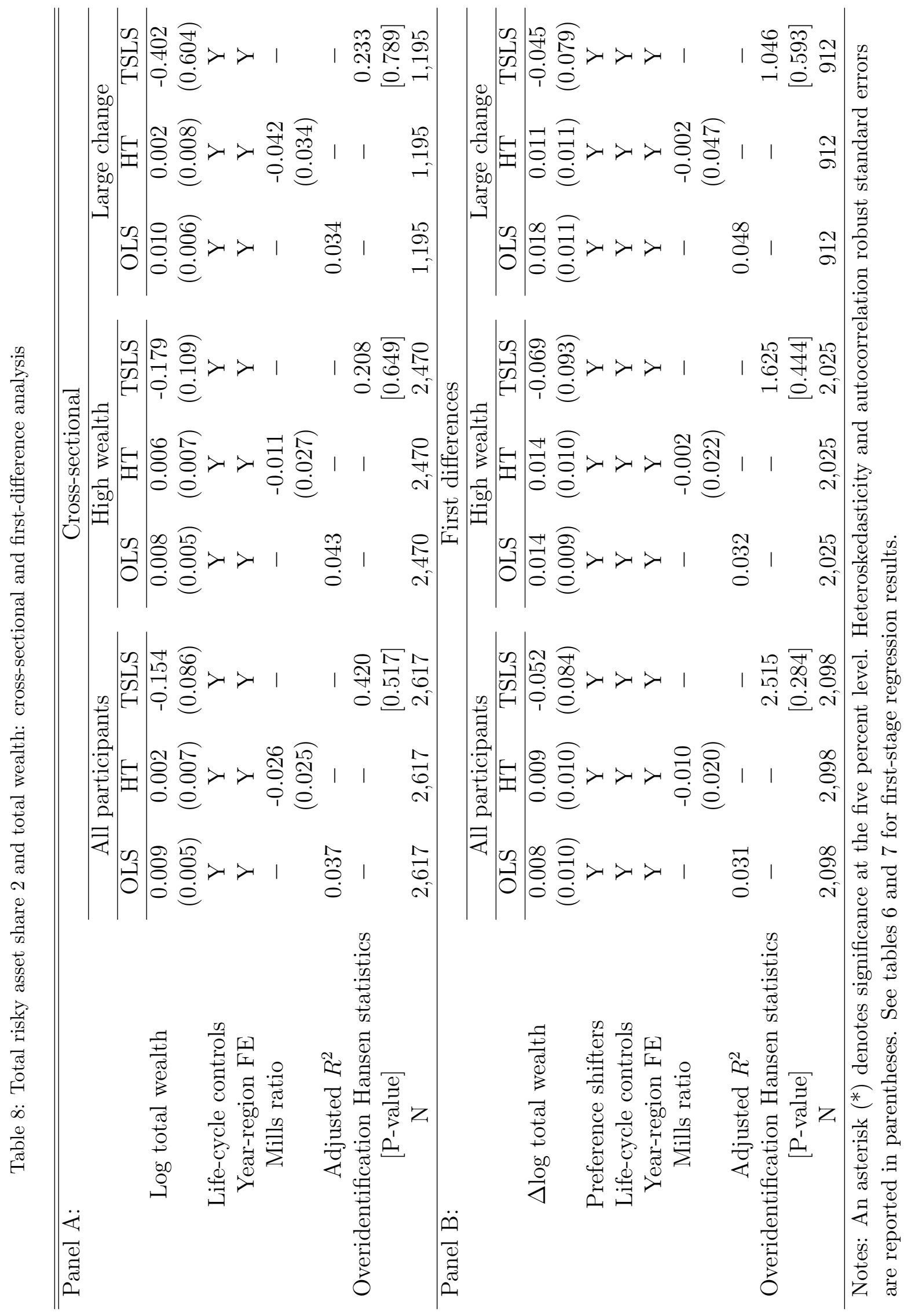




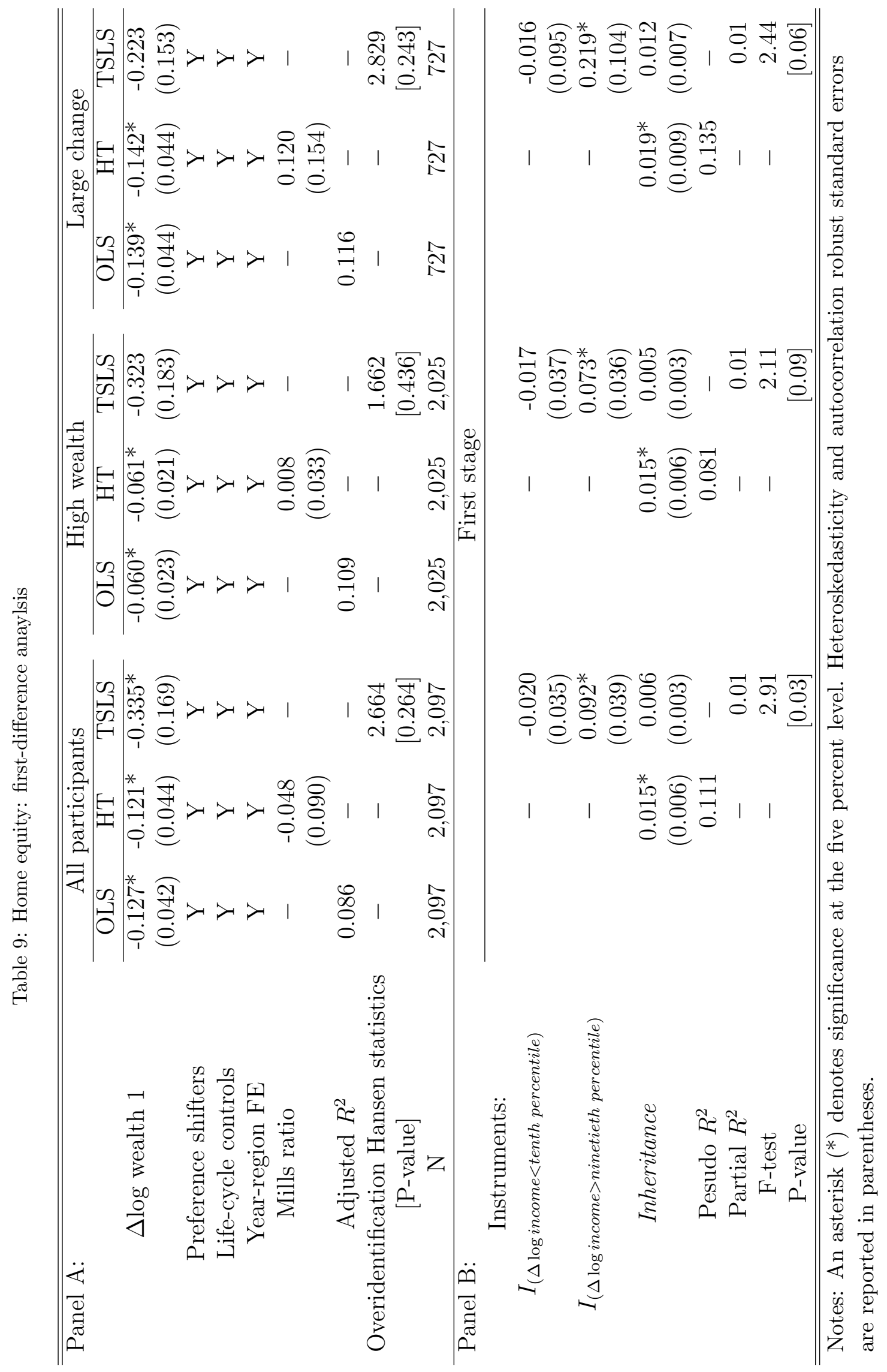




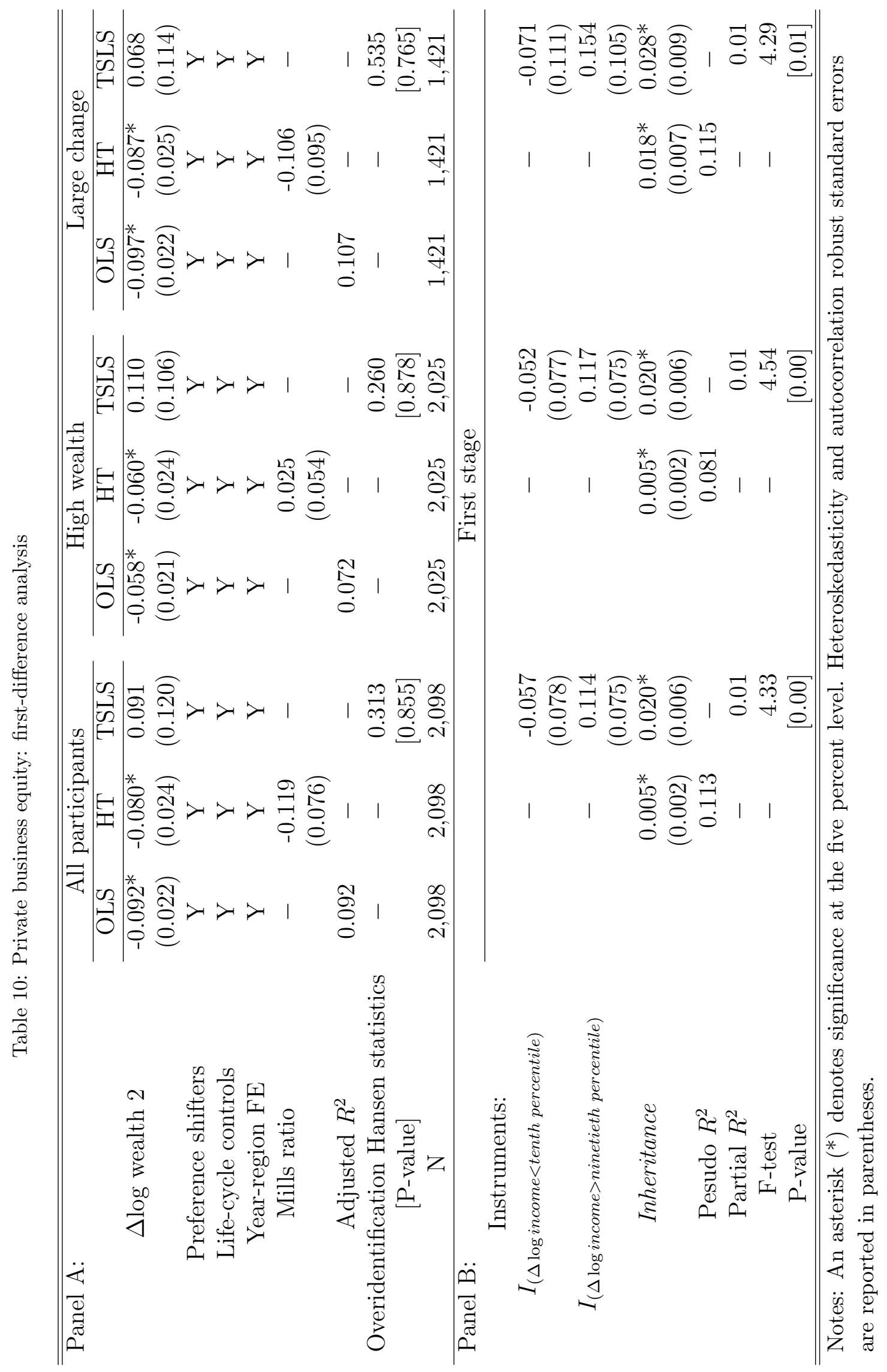




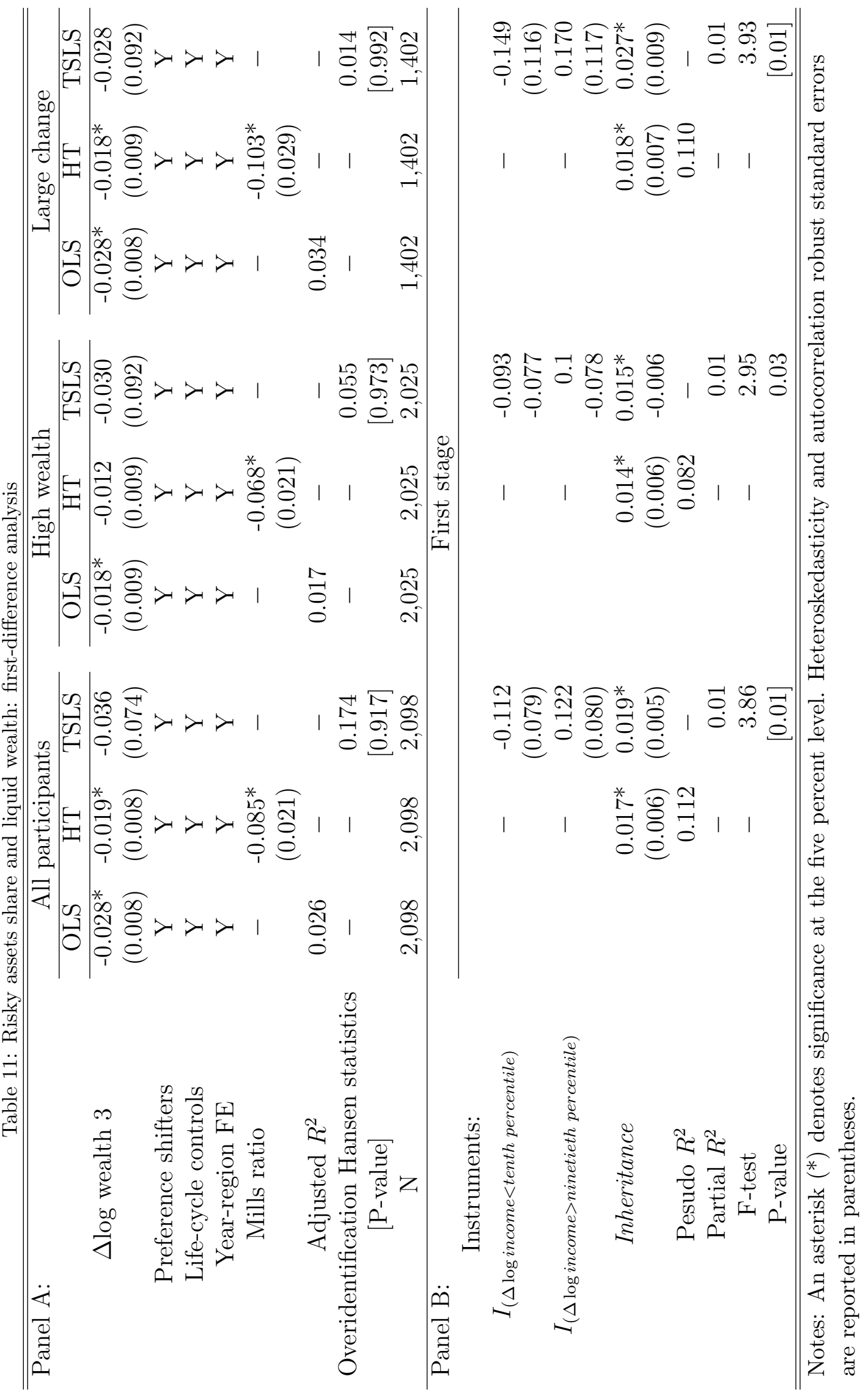


Figure 1: Distribution of relative risk aversion

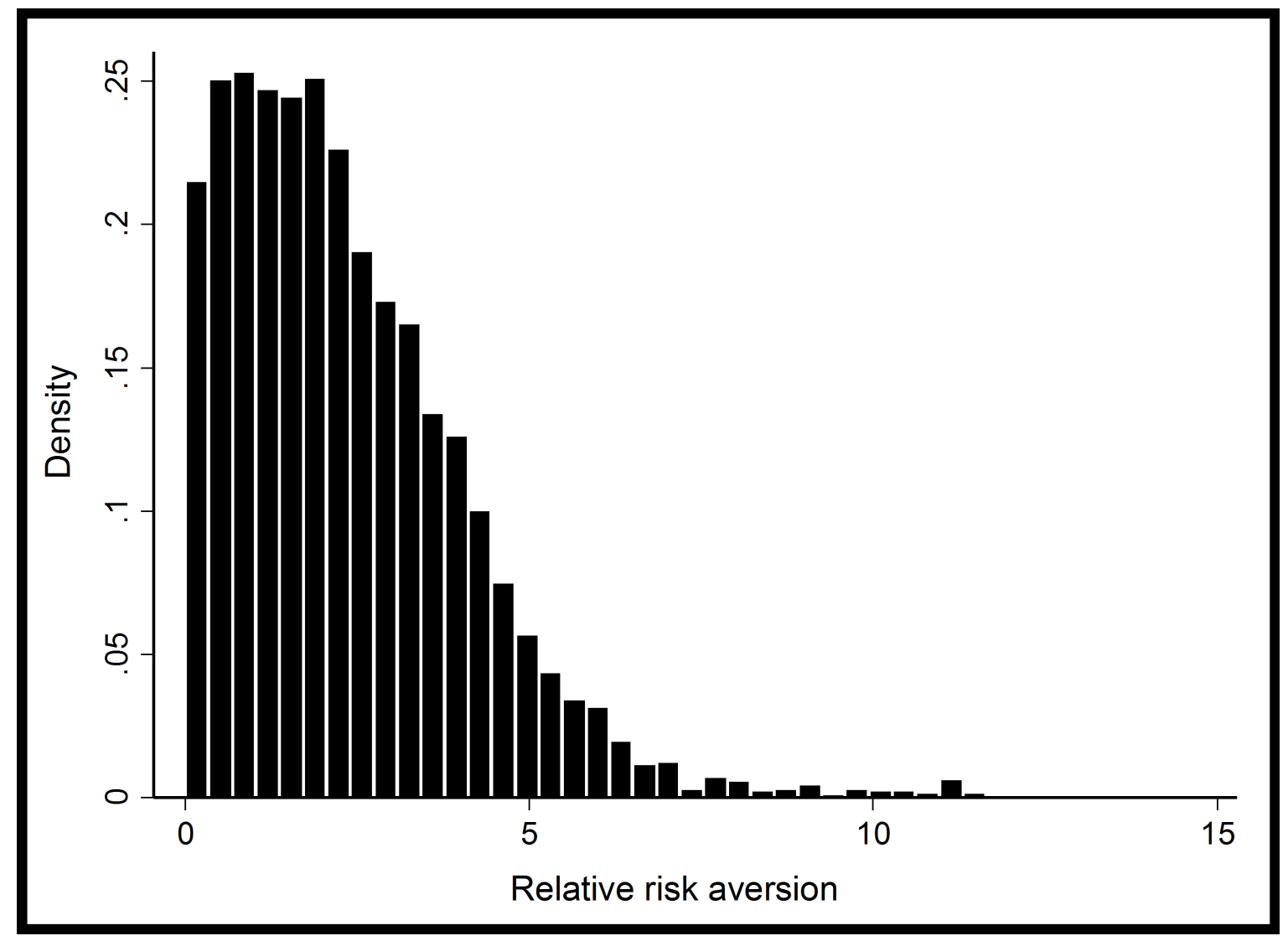


Figure 2: Distribution of relative risk aversion: high and low liquid wealth
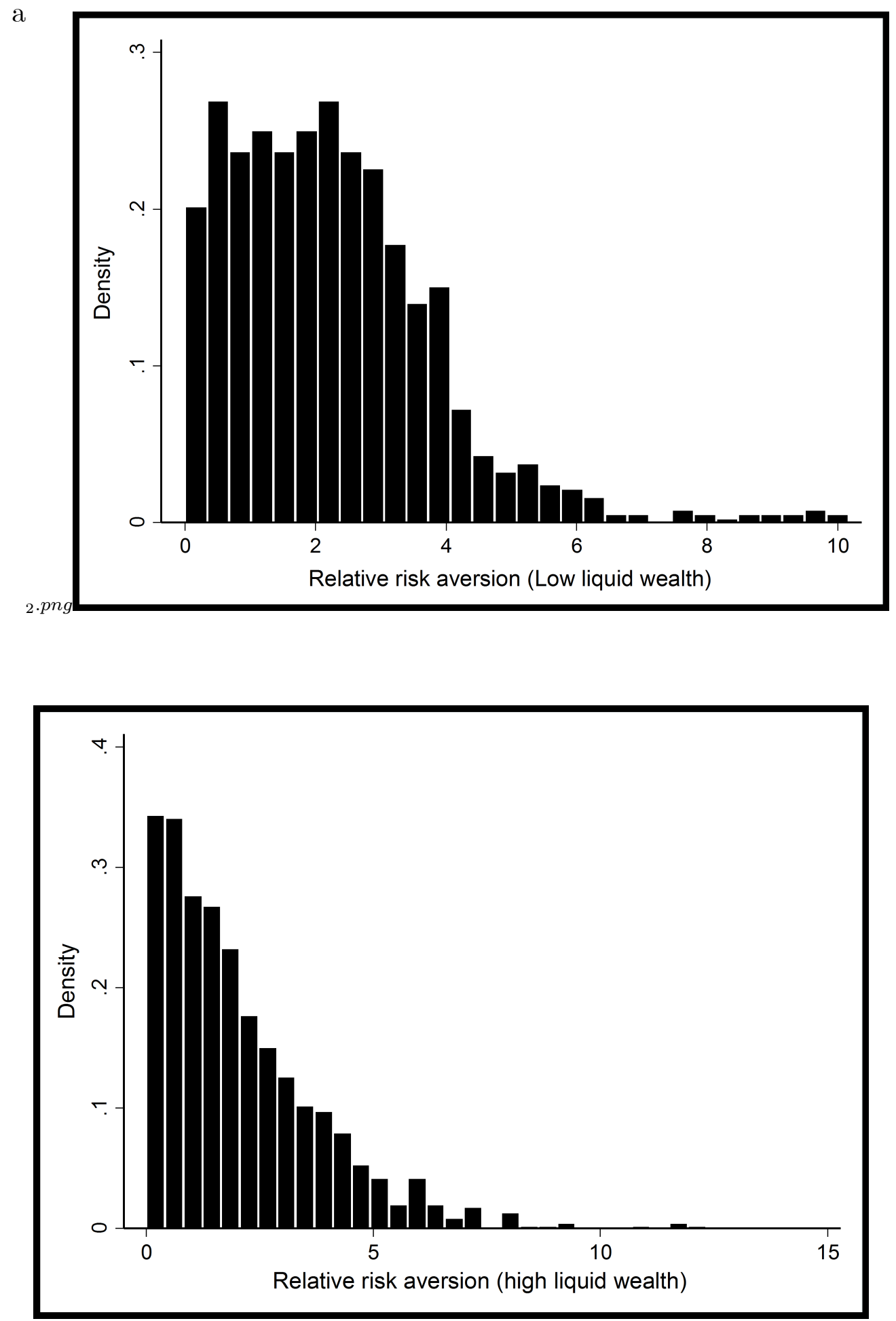